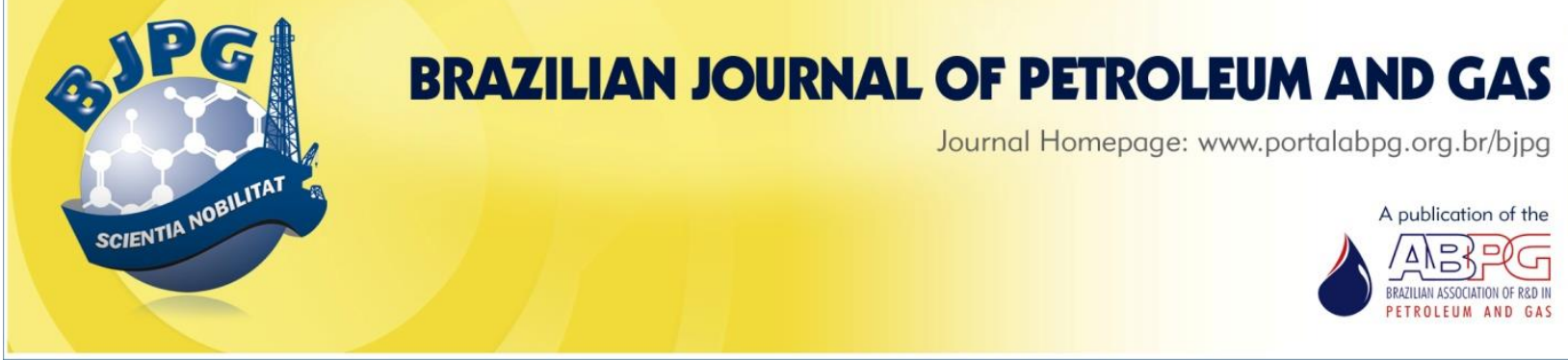

\title{
THE INFLUENCE OF CHEMICAL ADDITIVES IN FILTRATION CONTROL OF INHIBITED DRILLING FLUIDS
}

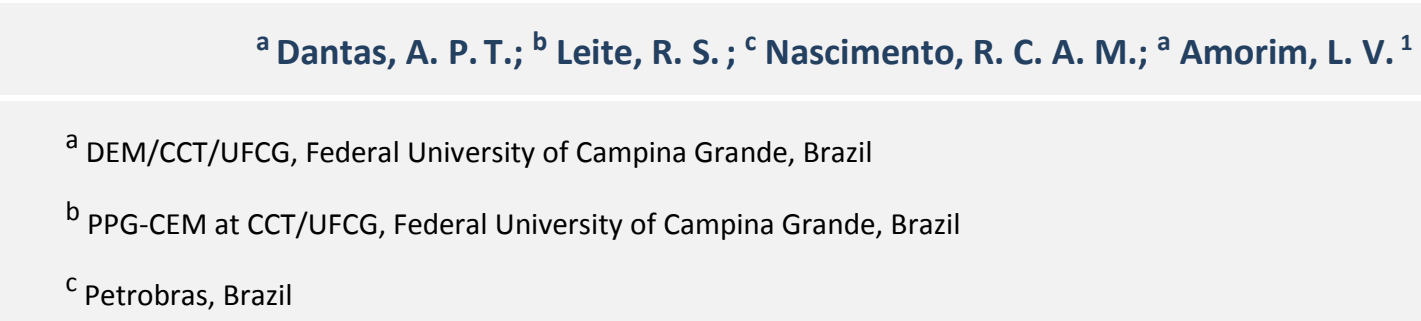

\section{ABSTRACT}

This work evaluates the influence of chemical additives, namely, starch, high-viscosity carboxymethylcellulose (HV-CMC), and calcite on rheological and filtration properties of inhibited drilling fluids composed by potassium citrate. A total of 11 experiments were conducted using a $2^{3}$-factorial design, three of which were in the central point. The concentration of starch varied from 0 to $0.0343 \mathrm{~kg} / \mathrm{L}$, the concentration of $\mathrm{HV}-\mathrm{CMC}$ ranged between 0 and $0.0043 \mathrm{~kg} / \mathrm{L}$, and the concentration of calcite from 0 to $0.071 \mathrm{~kg} / \mathrm{L}$. Rheological and filtration properties were determined for the studied fluids. According to the results, starch and HV-CMC influence statistically the rheological properties of the studied fluids. The filtration properties, on the other hand, are statistically affected by these additives. The best results for fluid loss were obtained with fluids comprising starch and calcite in high concentrations, or with starch, $\mathrm{HV}-\mathrm{CMC}$, and calcite in high concentrations.

\section{KEYWORDS}

drilling fluids; factorial design; rheology; filtration

\footnotetext{
${ }^{1}$ To whom all correspondence should be addressed.

Address: Federal University of Campina Grande, DEM/ CCT/ UFCG, Rua Aprígio Veloso, 882, Campina Grande- PB - Brazil. Zip Code: 58429-140|Telephone: (55) 83 2101-1483 |Fax: (55) 83 2101-1272 |e-mail: luciana@dem.ufcg.edu.br doi:10.5419/bjpg2014-0009
} 


\section{INTRODUCTION}

Oil well drilling is one of the main activities in oilfields. According to Meng et al. (2012), drilling fluids can be called the "blood" in drilling industry, playing a major role in drilling operations. This is because drilling fluids perform essential tasks, such as lubricating the drill bit, providing hydrostatic pressure, and removing drill cuttings. Another important function of the drilling fluid is to stop compacted clay minerals, commonly encountered in drilling operations, from taking up water from the drilling fluids and, consequently, swelling (Suter et al., 2011).

According to statistical investigations (Dzialowski et al., 1993), shales account for about $75 \%$ of the drilled sections in oil and gas wells, and cause approximately $90 \%$ of the wellbore instability-related problems during drilling operations. These formations are highly water reactive. The drilling fluid is responsible for preventing interactions with any water within the mud filtrate, because the stability of clay-rich shales is affected greatly by their complex physical and chemical interactions with drilling fluids (Suter et al., 2011; Van Oort, 2003).

Shale formations containing high fractions of clay minerals such as smectites, immediately take up water from the drilling fluid, resulting in rapid swelling and dispersion of the shale (Boek et al., 1995). These clay minerals have a high capacity of exchanging cations because of their negative charges on the outer surface, which make them able to react with the cations present in solutions (Rabe, 2003).

Shale formations have negatively affected drilling operations for many years. They interact with the drilling fluid, experience failure, and produce excessive solids to be removed from the well and from an enlarged borehole in which it is difficult to work (Lomba et al., 2000). Consequently, typical problems such as bit-balling, disintegration of cuttings, borehole wash-out, high torque and drag, and stuck pipes are often encountered as a result of water adsorption by water-sensitive shales (Steiger \& Leung, 1992).

As a solution to the problems mentioned above, the use of oil-based drilling fluids arises. These fluids have excellent properties such as stability, lubricity, and temperature stability (Mohamed et al., 2010). They have demonstrated to produce minimal shale/mud interactions in the past (Lomba et al., 2000). However, oil-based drilling fluids are environmentally unacceptable and are particularly hazardous to marine ecosystems. Consequently, much research has focused on improving the properties of water-based drilling fluids with the means of having comparable performance to that of oil-based drilling fluids (Suter et al., 2011). Unfortunately, when water-based fluids come into contact with shale formations there is a flow of ions and water into the shale due to differences in chemical and hydraulic potentials of the species in the pore and drilling fluid (Lomba et al., 2000). Their use facilitates clay hydration and swelling, which can have an adverse impact on drilling operations and may lead to significantly increased oil well construction costs (Anderson et al., 2010).

During the drilling practice in shale formations, additives such as rheological modifiers and shale inhibitors are frequently added into water-based drilling fluids to reduce clay mineral or shale swelling (Qu et al., 2009). Inhibited drilling fluids are used because of their special rheological properties, in particular, their ability to promote gelification under certain conditions and their susceptibility to thixotropy. Equally important is their capacity of forming a cake on the walls of the rock formation, which prevents the collapse of the pit walls. The cake stops the invasion of water in the geological formation both during drilling operations and at rest, when the drilling operation is stopped. A good drilling fluid presents great filtration properties to obtain a cake with adequate permeability. If the cake is very permeable, a great amount of the drilling fluid water will pass through the cake into the geological formation. If the cake is impermeable, its thickness may increase, which leads to a decrease in the pit diameter and an increase in the pressure inside the pit. As a result, the drilling will be difficult to maneuver (Chilingarian \& Vrabutr, 1983).

Usually, salts are used as inhibitors of active formations in order to reduce the hydraulic flow, mainly due to the viscosity of its filtrates and their capability of stimulating the flow of water from the clay formation to the drilling fluid, reversing the flow, reducing the formation hydration, and stabilizing the pore pressure around the well (Guimarães \& Rossi, 2008). In this study, potassium citrate was used as inhibitor. 
The measurements of static filtration and wall cake thickness of a mud are essential to the control and treatment of drilling fluids. These characteristics are influenced by the nature and quantity of solids in the fluid and their physical and chemical interactions with the liquid. Sodium bentonite, synthetic, and biopolymers are commonly used as filtration control agents (Hamida et al., 2010).

One of the desired properties of a drilling mud is that it should minimize fluid loss from the wellbore into the surrounding permeable formation. This is achieved by creating a low-permeability filter cake at the surface of the wellbore (Sherwood \& Meeten, 1997).

As described by Ding et al. (2002), at an early time of drilling, as soon as the drilling bit penetrates a formation, a quick mud invasion (spurt loss) into the formation occurs. The mud invasion is caused by the absence of a filter cake to prevent the invasion of solid particles into the oil formation. During this period, there is a progressive deposition of solid particles on the porous medium, which creates an internal filter cake. This episode is called "spurt period", which generally is very short, lasting only a few minutes. At the end of the spurt period, an internal filter cake is completely formed, after which most of the solid particles are retained inside the wellbore, creating an external filter cake layer (mud cake). This mud cake layer controls the invasion rate of mud filtrate. Meanwhile, the mud filtrate continues to invade the formation by traversing the mud cake and the internal filter cake.

The starch, a polymer that presents a structural molecule of a slightly anionic character, considered hydrophilic, is among the additives studied in this work. This feature renders it able to absorb large quantities of water, which allows it to act as a controller of fluid loss in the formation. Another important feature of this polymer is the fact that it has large moieties on its chain, which helps minimizing the penetration of drilling fluids in the formation (Guimarães \& Rossi, 2008).

Carboxymethylcellulose (CMC) is a polymer derived from cellulose which is insoluble in water. Therefore, in order to become soluble, it is modified to the form of a polyelectrolyte (Amorim, 2003). According to Pereira apud Amorim (2003), the CMC is largely used in water-based fluids as a filtrate reducer, to minimize losses by filtration and produce very thin filter cakes that are capable of preventing the flow of fluid through the geological formations that are being drilled.

Calcium carbonate $\left(\mathrm{CaCO}_{3}\right)$, or calcite, on the other hand, can be used as a sealant of the cake pores. It helps to reduce fluid loss due to shutting of the pores of the filter cake, thereby increasing its impermeability more quickly.

Based on the above considerations, the aim of this work is to evaluate the influence of chemical additives such as starch, high-viscosity carboxymethylcellulose (HV-CMC) and calcite on rheological (apparent viscosity, plastic viscosity, and yield limit) and filtration properties (fluid loss, cake thickness, permeability, and spurt loss) of inhibited drilling fluids composed by potassium citrate.

\section{MATERIALS AND METHODS}

\subsection{Materials}

Water-based fluids developed by Lucena (2011) were used to prepare the drilling fluids. The additives employed in this work, with their corresponding functions and concentrations, are listed in Table 1.

Table 1. Additives used in the preparation of the drilling fluids.

\begin{tabular}{ccc}
\hline Additive & Function & Concentration range \\
\hline Water (L) & Additives dispersion & 0.35 \\
Anti-foam (L) & Avoids excessive foam & 0.0004 \\
Xanthan gum (kg/L) & Viscosifier & 0.0043 \\
Starch (kg/L) & Filtrate reducer & 0.0 to 0.0343 \\
HV-CMC (kg/L) & Viscosifier & 0.0 to 0.0043 \\
MgO (kg/L) & pH controller & 0.0028 \\
Potassium Citrate (kg/L) & Clay inhibitor & 0.0457 \\
Bactericide (kg/L) & Prevents the additives degradation & 0.0020 \\
Lubricant (L) & Reduces the friction & 0.0105 \\
Calcite (kg/L) & Sealant & 0.0 to 0.0714 \\
\hline
\end{tabular}




\subsection{Methods}

\subsubsection{Development of drilling fluids formulations}

A factorial experimental design type $2^{3}$, with three experiments at the center point, was used to develop the studied drilling fluids' formulations, totaling 11 experiments. A regression of the experimental data was done using the Statistica ${ }^{\circ}$ software, version 5.0 (Statsoft, 2004). The codified levels and the real values of the input variables used in the planning are shown in Table 2, and the experimental planning matrix is shown in Table 3.

\subsubsection{Preparation of drilling fluids}

The drilling fluids were prepared using a Hamilton Beach 936 high-rotation mechanical agitator. Initially, the anti-foam was added to the water, and after 300 seconds stirring at 13,000 $\mathrm{rpm}$, the other additives were added, one at a time. Each additive remained another 300 seconds at low agitation, except the starch, the HV-CMC and the calcite, which were kept under stirring for 600 seconds. Finally, the last additive was added to the drilling fluid and the stirring speed was increased to $15,000 \mathrm{rpm}$. After preparation, each fluid remained at rest for 24 hours. Then, the tests were conducted to determine the rheological parameters.

\subsubsection{Rheological study}

The rheological properties of the fluids in this research were tested with a Fann 35A viscometer. After 24 hours, the fluid was stirred for 300 seconds under constant agitation at 13,000 rpm, using the Hamilton Beach agitator. Then, the rheological study was done using the viscometer, under API rules (2005). Apparent viscosity (AV) is the value obtained at $600 \mathrm{rpm}$ divided by 2 , in $\mathrm{CP}$, and plastic viscosity (PV) is the difference between the values obtained at $600 \mathrm{rpm}$ and $300 \mathrm{rpm}$, also given in $\mathrm{CP}$. Then, the viscosities were converted to Pa.s ( $\left.\mathrm{CP} \times 10^{3}\right)$. The yield limit (YL) is the difference between the value obtained on reading at $300 \mathrm{rpm}$ and the plastic viscosity, in $\mathrm{Pa}$.

\subsubsection{Fluid loss}

After the rheological study, the fluid loss was determined by agitating the drilling fluid for 60 seconds at constant speed. The mud sample was then transferred to the API filter press cell. A pressure of approximately $7.0 \mathrm{kgf} / \mathrm{cm}^{2}$ was applied during 1800 seconds.

Table 2. Codified levels and real values of the input variables used in the factorial planning.

\begin{tabular}{cccc}
\hline \multirow{2}{*}{ Input variables } & \multicolumn{3}{c}{ Codified levels } \\
\cline { 2 - 4 } & -1 & 0 & +1 \\
\hline Starch $(\mathrm{kg} / \mathrm{L})$ & 0.0 & 0.0171 & 0.0343 \\
HV-CMC (kg/L) & 0.0 & 0.0021 & 0.0043 \\
Calcite (kg/L) & 0.0 & 0.0357 & 0.0714 \\
\hline
\end{tabular}

Table 3. Experimental planning matrix.

\begin{tabular}{cccc}
\hline Fluids & $\begin{array}{c}\text { Concentration of } \\
\text { Starch }\end{array}$ & $\begin{array}{c}\text { Concentration of } \\
\text { HV-CMC }\end{array}$ & $\begin{array}{c}\text { Concentration of } \\
\text { Calcite }\end{array}$ \\
\hline F1 & -1 & -1 & -1 \\
F2 & +1 & -1 & -1 \\
F3 & -1 & +1 & -1 \\
F4 & +1 & +1 & -1 \\
F5 & -1 & -1 & +1 \\
F6 & +1 & -1 & +1 \\
F7 & -1 & +1 & +1 \\
F8 & +1 & +1 & +1 \\
F9 & 0 & 0 & 0 \\
F10 & 0 & 0 & 0 \\
F11 & 0 & 0 & 0 \\
\hline
\end{tabular}




\subsubsection{Mud cake thickness}

To determine the mud cake thickness, a methodology developed by Farias (2005) was adapted based on the API 13B-1 (2003) standard procedure. The filter paper was collected with the cake formed during the assay to obtain the fluid loss. Then, this paper was washed out three times at a constant flow of approximately $30.5 \mathrm{~mL} / \mathrm{s}$, at a distance close to $7 \mathrm{~cm}$ from the flow controller, with a diameter of $1.5 \mathrm{~cm}$ and an angle of attack of approximately $45^{\circ}$. After washing, the filter paper was inserted in two glass slides and submitted to a pressure of approximately $277.6 \mathrm{~Pa}$ for about 120 seconds with the aim of equalizing the surface of the cake. After this period, the cake thickness was measured using an extensometer. Five measures of the thickness of the slides and the filter paper with the cake in distinct points were made. Then, the arithmetical average of the five readings was calculated.

\subsubsection{Permeability}

The mud cake permeability was determined with Equation (1) (Lomba, 2010):

$$
K=Q_{f} \cdot \varepsilon, \mu .8,95 \times 10^{-5}
$$

Where:

$\mathrm{K}=$ mud cake permeability, in $\mathrm{mD}$;

$\mathrm{Q}_{\mathrm{f}}=$ fluid loss, in $\mathrm{cm}^{3}$;

$\varepsilon=$ mud cake thickness, in $\mathrm{mm}$;

$\mu=$ viscosity of the fluid's liquid phase, in CP.

\subsubsection{Spurt loss}

There is a spurt loss at the start of a filter test made on paper before filtration proper begins, and, thereafter, filtrate volume comes proportional to the square root of the time interval. This property provides the instantaneous loss of fluid which occurs before mud cake formation and is a good indicator of the amount of suspended solids in the fluid. The initial filtrate was determined according to the ANSI/API 13I standard and measured in the following times: $60,300,450,600,900,1500$, and 1800 seconds. The values obtained were represented graphically as accumulated fluid loss, as a function of the square root of time.

\section{RESULTS AND DISCUSSION}

Table 4 presents the results of apparent viscosity (AV), plastic viscosity (PV), yield limit (YL), fluid loss (FL), cake thickness (CT), and permeability (K) obtained for the fluids prepared according to the experimental design shown in Table 3. Based on these results, it was observed that increasing the concentration of HV-CMC largely affected the rheological properties of the fluids. In particular, it was observed that the values of the rheological properties increased to a larger extent when the concentrations of $\mathrm{HV}-\mathrm{CMC}$ and starch were increased together. This result is evident when comparing the results obtained for fluids $\mathrm{F} 4$ and F8 (composed by the maximum amounts of HV-CMC and starch), as well as F3 and F7 (composed by the maximum amount of HV-CMC, however without starch), with the other fluids.

Table 4. Apparent viscosity (AV), plastic viscosity (PV), yield limit (YL), fluid loss (FL), cake thickness (CT), and permeability $(\mathrm{K})$ of the inhibited fluids.

\begin{tabular}{|c|c|c|c|c|c|c|}
\hline Fluids & AV $\left(10^{-3}\right.$ Pa.s $)$ & PV (10 $0^{-3}$ Pa.s $)$ & $\mathrm{YL}(\mathrm{Pa})$ & $\mathrm{FL}\left(10^{-3} \mathrm{~L}\right)$ & CT $\left(10^{-3} \mathrm{~m}\right)$ & $\mathrm{K}\left(10^{-3} \mathrm{mD}\right)$ \\
\hline F1 & 17.5 & 8.5 & 18.0 & 33.4 & 0.721 & 2.16 \\
\hline F2 & 32.6 & 16.8 & 31.8 & 20.0 & 0.539 & 0.96 \\
\hline F3 & 50.5 & 22.0 & 57.0 & 9.0 & 1.071 & 0.86 \\
\hline F4 & 92.0 & 43.5 & 97.0 & 11.4 & 0.920 & 0.94 \\
\hline F5 & 21.0 & 12.0 & 18.0 & 10.2 & 0.553 & 0.50 \\
\hline F6 & 42,5 & 23.0 & 39.0 & 5.2 & 0.518 & 0.24 \\
\hline F7 & 52.0 & 21.5 & 61.0 & 11.6 & 0.885 & 0.92 \\
\hline F8 & 92.5 & 37.0 & 111.0 & 5.8 & 0.878 & 0.45 \\
\hline F9 & 44.0 & 21.0 & 46.0 & 9.0 & 0.412 & 0.33 \\
\hline F10 & 43.5 & 21.0 & 45.0 & 8.4 & 0.626 & 0.47 \\
\hline F11 & 42.5 & 20.0 & 45.0 & 9.8 & 0.730 & 0.64 \\
\hline
\end{tabular}


Table 5. Analysis of variance (ANOVA) and codified mathematical models of the AV, PV, YL, FL, CT, and $K$ of the inhibited fluids for the applied experimental planning.

\begin{tabular}{ccccccc}
\hline Variation source & AV & PV & YL & FL & CT & K \\
\hline Correlation coefficient (R) & 0.991 & 0.989 & 0.990 & 0.939 & 0.790 & 0.837 \\
\% of explained variation* & 98.2 & 97.8 & 98.0 & 88.2 & 63.0 & 70.1 \\
${\text { Fcalculated } / F_{\text {tabulated }}}_{\text {Codified mathematical models for the inhibited drilling fluids }}$ & 5.88 & 4.73 & 5.42 & 0.81 & 0.23 & 0.12 \\
\hline $\mathrm{AV}\left(10^{-3} \mathrm{~Pa} . \mathrm{S}\right)=\left(48.24^{* *} \pm 1.56\right)+\left(14.83 \mathrm{~A}^{* *} \pm 1.83\right)+\left(21.67 \mathrm{~B}^{* *} \pm 1.83\right)+\left(5.67 \mathrm{AB}^{* *} \pm 1.83\right)$ \\
\hline $\mathrm{PV}\left(10^{-3} \mathrm{~Pa} . \mathrm{s}\right)=\left(22.39^{* *} \pm 0.71\right)+\left(7.03 \mathrm{~A}^{* *} \pm 0.84\right)+\left(7.97 \mathrm{~B}^{* *} \pm 0.84\right)$ \\
\hline $\mathrm{YL}(\mathrm{Pa})=\left(51.7^{* *} \pm 1.96\right)+\left(15.59 \mathrm{~A}^{* *} \pm 2.3\right)+\left(27.41 \mathrm{~B}^{* *} \pm 2.3\right)+\left(6.91 \mathrm{AB} \mathrm{B}^{* *} \pm 2.3\right.$ \\
\hline $\mathrm{FL}\left(10^{-3} \mathrm{~L}\right)=\left(12.20^{* *} \pm 1.31\right)-\left(5.075 \mathrm{C}^{* *} \pm 1.54\right)+(4.38 \mathrm{BC} * * \pm 1.54)$ \\
$\mathrm{CT}\left(10^{-3} \mathrm{~m}\right)=\left(0.776285^{* *} \pm 0.067040\right)$ \\
$\mathrm{K}(\mathrm{mD})=\left(0.0008^{* *} \pm 0.00013\right)$ \\
\hline
\end{tabular}

Being: $\mathrm{A}=$ starch, $\mathrm{B}=\mathrm{HV}-\mathrm{CMC}$ and $\mathrm{C}=$ calcite.

${ }^{*} R^{2}=\left(\frac{S Q_{R}}{S Q_{T}}\right) \times 100$, being: $\mathrm{SQ}_{R}$ the quadratic sum from the regression, $\mathrm{SQ}_{\mathrm{T}}$ the total quadratic sum

** Statistically significant at the level of $95.0 \%$ of reliability

It is known that the HV-CMC is a viscosifier, and, as expected, this characteristic was confirmed in the assays. Alternatively, the starch also contributed to the increase in fluid viscosity, in spite of its use as a filtrate reducer. This can be confirmed by comparing the results for fluids F1 and F2, both with the same base composition, but with the addition of starch in F2. The same conclusion can be made by comparing fluids $\mathrm{F} 3$ and $F 4$, and fluids F7 and F8, since the difference in composition is only the concentration of starch.

With respect to calcite, an increase in viscosity is expected with the increase of its concentration, given that this additive has low degree of solubility and can be found in fluids in the form of a dispersed solid, which increases flow resistance. In general, this behavior was observed in the studied fluids.

Regarding the filtration properties, it was observed that fluids F6 and F8 presented lower FL values, which is desirable, ranging from 0.0052 to $0.0058 \mathrm{~L}$, respectively. Fluid F1 showed higher FL $(0.0334 \mathrm{~L})$, which was due to the fact that it does not contain any filtrate reducer or sealant in its composition. The high values for fluid loss, on another hand, may indicate excessive invasion of the filtrate in geological formations.
From Table 4, it was observed that fluid F1 showed high permeability when compared with other fluids. The high permeability in this case is related to the absence of the filtrate reducer, the sealant and the viscosifier, and can be directly related to fluid loss, which was also high, in that filtration control is impaired as the permeability of the mud cake increases. Also, fluids F6 and F9 had lower permeability values. The mud cake permeability is influenced by the nature of the colloidal particles in the system, as well as by the size and shape of these particles. Macromolecular organic compounds, such as starch, reduce the mud cake permeability because of the deformation capacity and the small size of their hydrolyzed molecules (Lomba, 2010).

Table 5 shows the analysis of variance (ANOVA) and the codified mathematical models (regression equation) for the following parameters of the studied fluids: apparent viscosity (AV), plastic viscosity (PV), yield limit (YL), fluid loss ( $F L)$, cake thickness (CT), and mud cake permeability (K).

For the inhibited fluids prepared according to the experimental planning, the analysis of the statistical significance showed that the correlation coefficients (R) and the explained variation coefficients of the experimental results for AV, PV, 
and $\mathrm{YL}$ were satisfactory, with values around 0.98 and $98 \%$, respectively. This indicates that the mathematical models presented have more than $98 \%$ of the variations obtained explained by the model. For variables $\mathrm{FL}, \mathrm{CT}$, and $\mathrm{K}$ the values of the correlation coefficients (R) and the explained variation coefficients were higher than 0.79 and $62 \%$, with over $62 \%$ of the variations obtained explained by the model. The determination or explanation coefficient $\left(R^{2}\right)$ quantifies the quality of the fitting, as it provides a measure of the proportion of the variation explained by the regression equation in relation to the total variance of the responses, ranging from 0 to $100 \%$ (Rodrigues \& lema, 2010).

According to the mathematical models obtained, only calcite and the interaction of HVCMC and calcite statistically influence FL. For CT and $\mathrm{K}$, only the average had statistically significant influence. This is due to the low values of the correlation coefficient and percentage of explained variation.

Test $\mathrm{F}$ presents the ratio between $\mathrm{F}_{\text {calculated }}$ and $F_{\text {tabulated. }}$ When this ratio is higher than 1 , the regression is statistically significant (Rodrigues \& lema, 2010). For the evaluated parameters, the variable $\mathrm{PV}$ presented Test $\mathrm{F}$ values higher than 1 , indicating that the model is statistically significant at a $95 \%$ confidence level. For the properties AV and $\mathrm{YL}$, statistically significant and predictive models were obtained at a $95 \%$ confidence level, since the ratio between $F_{\text {calculated }}$ and $F_{\text {tabulated }}$ were higher than 5 .

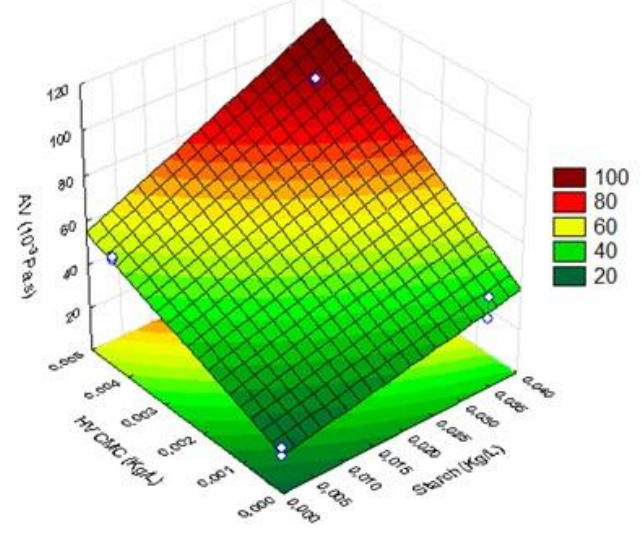

(a)
Figures 1, 2, and 3 present the response surfaces obtained from the mathematical models presented on Table 5 to $\mathrm{AV}, \mathrm{PV}$, and $\mathrm{YL}$, respectively.

By analyzing Figure 1(a), it can be observed that highest values of $A V$ are obtained when the fluids are prepared using higher concentrations of starch and HV-CMC. This behavior was observed when setting the calcite concentration in $0.0357 \mathrm{Kg} / \mathrm{L}$. Figure $1(b)$ shows that higher values of $A V$ are obtained using higher concentrations of HV-CMC, and calcite does not statistically influence this variable. It validates the results obtained using the mathematical model. This behavior was observed by setting the starch concentration in $0.0343 \mathrm{Kg} / \mathrm{L}$.

Analyzing the surface responses showed in Figures 2 and 3 to the variables $P V$ and $Y L$, respectively, the same behavior presented by $A V$ : higher values of $P V$ and $Y L$ are obtained when the fluids are prepared using higher concentrations of HV-CMC and starch, while the calcite does not influence these variables statistically.

By analyzing Figures 1, 2 and 3, it can be noted that the highest values of the rheological properties $\mathrm{AV}, \mathrm{PV}$, and $\mathrm{YL}$ occur when higher concentrations of starch and HV-CMC are used. Calcite, on the other hand, does not have much influence on these properties.

Since the mathematical models for $\mathrm{FL}, \mathrm{CT}$, and $\mathrm{K}$ were not statistically significant, the response surfaces were obtained in order to analyze trends only.

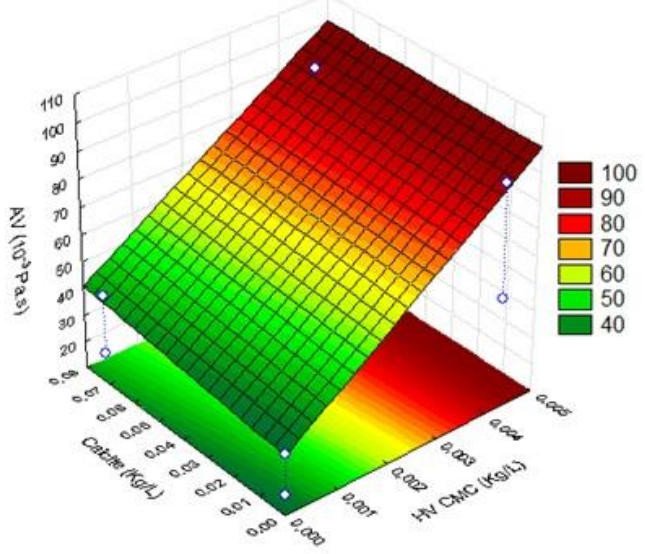

(b)

Figure 1. Response surfaces for AV, setting: (a) concentration of calcite at $0.0357 \mathrm{Kg} / \mathrm{L}$ and (b) concentration of starch at $0.0343 \mathrm{Kg} / \mathrm{L}$. 


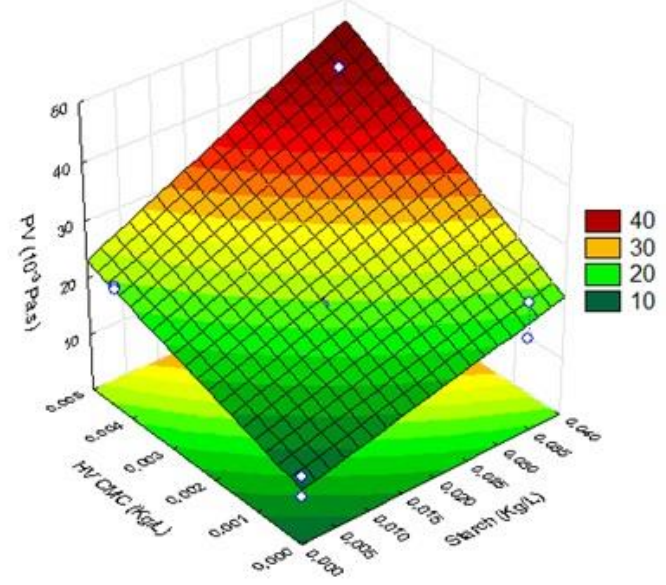

(a)

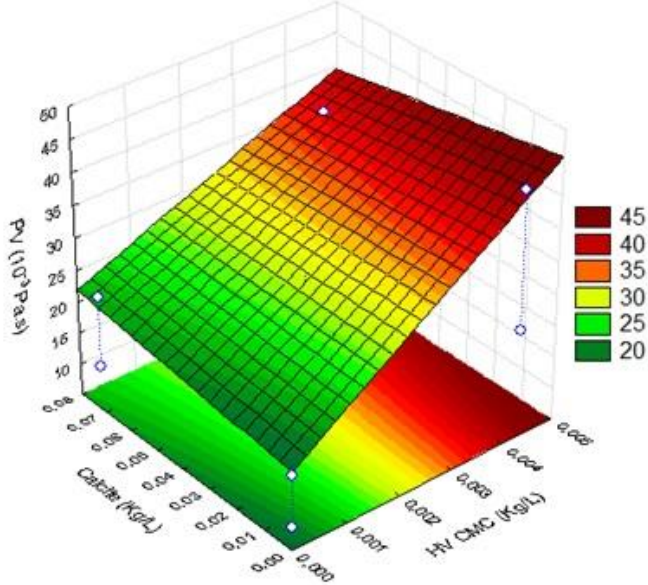

(b)

Figure 2. Response surfaces for PV, setting: (a) concentration of calcite at $0.0357 \mathrm{Kg} / \mathrm{L}$ and (b) concentration of starch at $0.0343 \mathrm{Kg} / \mathrm{L}$.

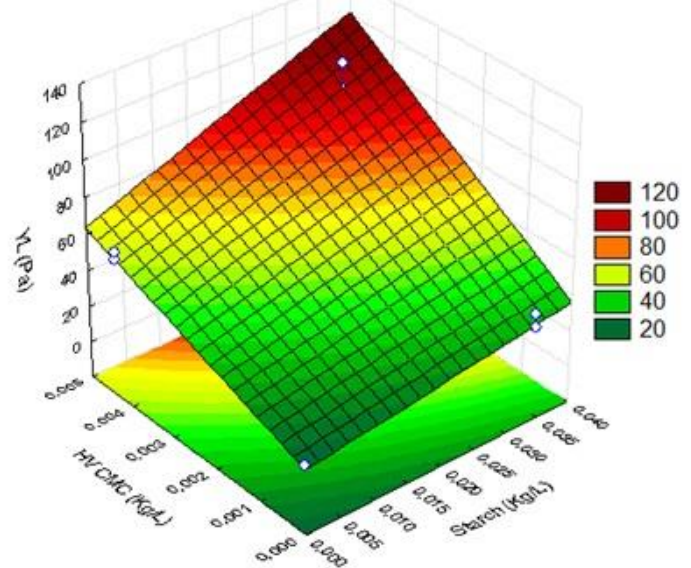

(a)

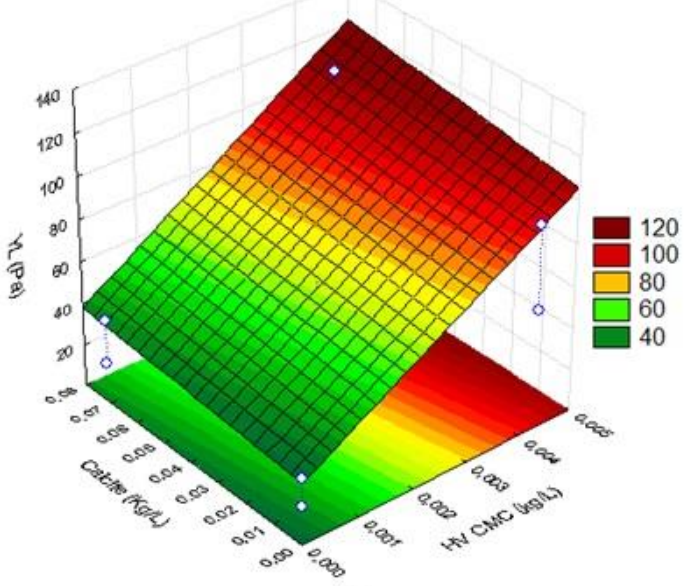

(b)

Figure 3. Response surfaces for $\mathrm{YL}$, setting: (a) concentration of calcite at $0.0357 \mathrm{Kg} / \mathrm{L}$ and (b) concentration of starch at $0.0343 \mathrm{Kg} / \mathrm{L}$.

Figures 4, 5 and 6 present the response surfaces obtained from the mathematical models presented on Table 5 to $\mathrm{FL}, \mathrm{CT}$, and $\mathrm{K}$, respectively.

The analysis of Figure 4(a) confirms that lower, although better values of $\mathrm{FL}$ are obtained by employing higher concentrations of calcite. They are little influenced by HV-CMC, however. From Figure 4(b), it was observed that higher concentrations of starch can contribute to reduce the values of $\mathrm{FL}$ and that higher concentrations of $\mathrm{HV}$-CMC increase the values of FL.
For the variable $\mathrm{CT}$, from Figures 5(a) and 5(b), one can observe that the lowest values occur with lower concentrations of HV-CMC, which may be caused due to the lower amount of solids present in the fluids, while the calcite and starch do not influence these variables statistically. From the analysis of Figures $6(a)$ and $6(b)$, it is suggested that lower values of $\mathrm{K}$ can be obtained when preparing the fluids with higher concentrations of calcite and starch. 


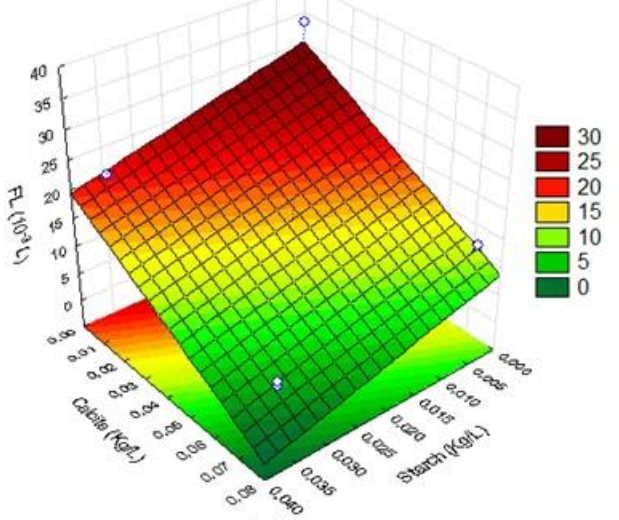

(a)

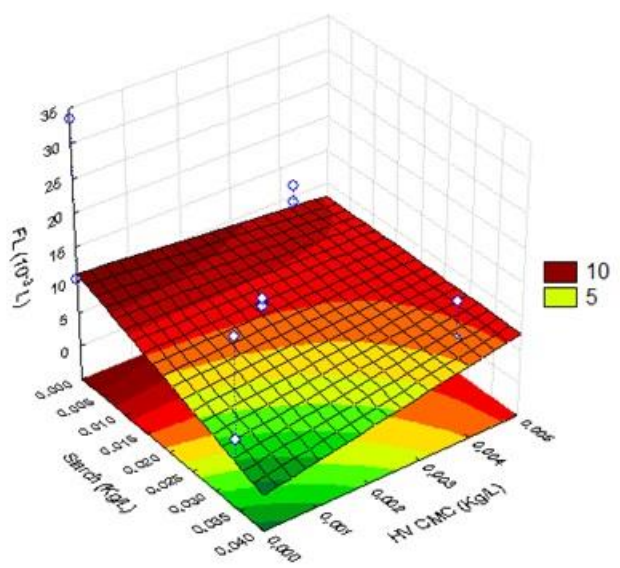

(b)

Figure 4. Response surfaces for FL, setting: (a) concentration of HV-CMC at $0 \mathrm{~kg} / \mathrm{L}$ and (b) concentration of calcite at $0.0714 \mathrm{~kg} / \mathrm{L}$.

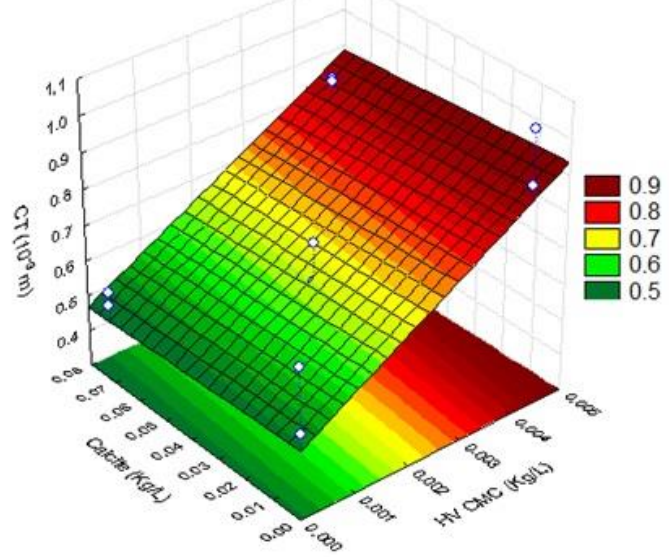

(a)

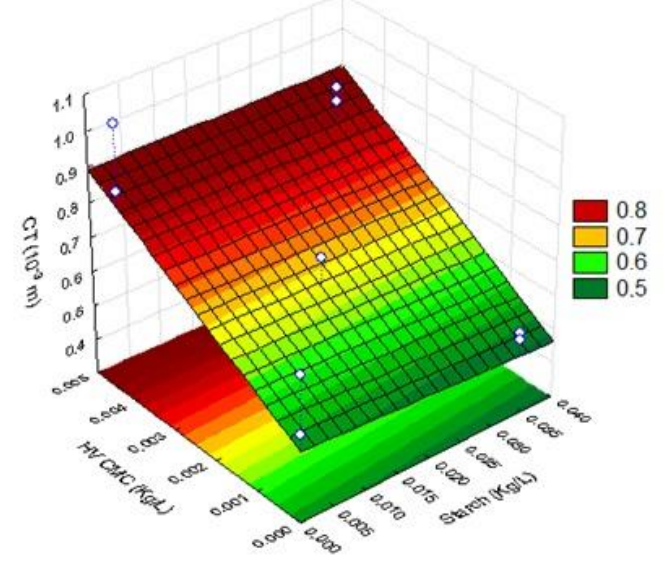

(b)

Figure 5. Response surfaces for CT, setting: (a) concentration of starch at $0.0343 \mathrm{~kg} / \mathrm{L}$ and (b) concentration of calcite at $0.0714 \mathrm{~kg} / \mathrm{L}$.

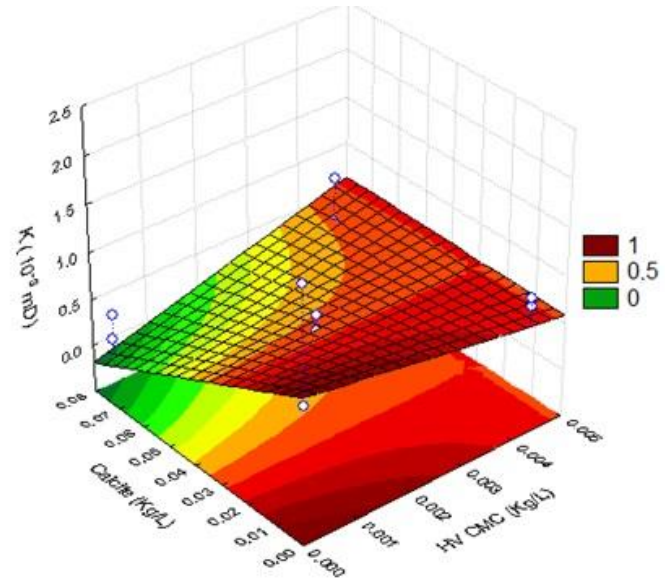

(a)

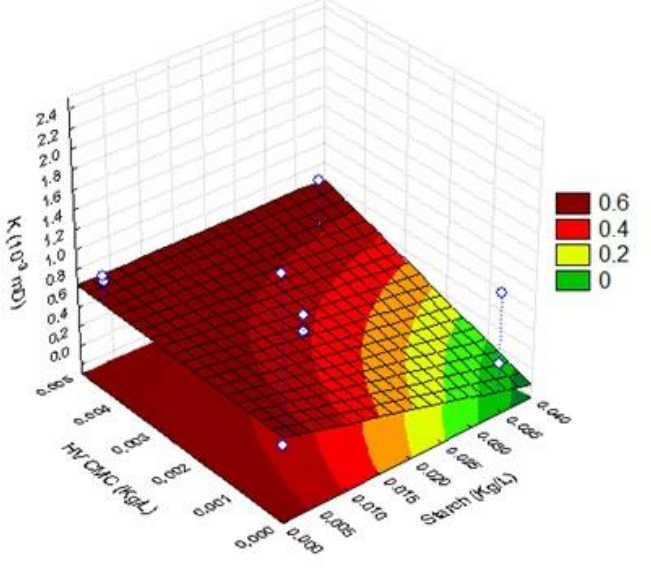

(b)

Figure 6. Response surfaces for K, setting: (a) concentration of starch at $0.0343 \mathrm{~kg} / \mathrm{L}$ and (b) concentration of calcite at $0.0714 \mathrm{~kg} / \mathrm{L}$. 


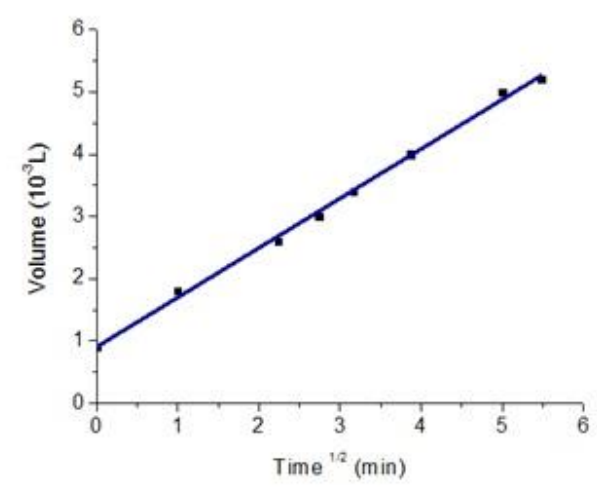

(a)

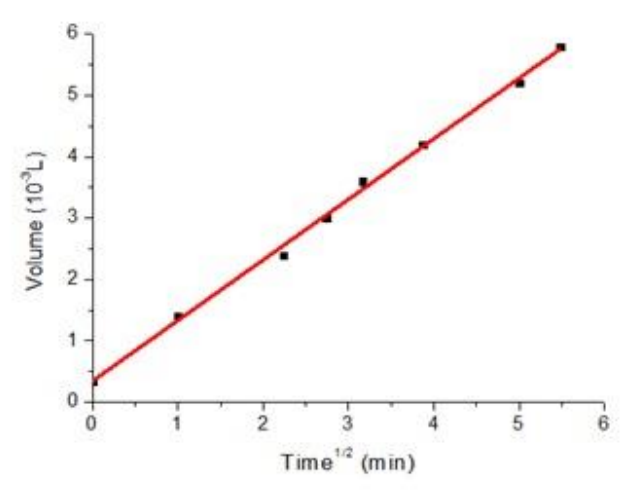

(b)

Figure 7. Plots of $F L$ versus $t^{1 / 2}$ for fluids $F 6(a)$ and $F 8(b)$.

Considering the drilling fluids F6 and F8 as the ones that presented the best results for filtration control, plots of $\mathrm{FL}$ versus $\mathrm{t}^{1 / 2}$ for fluids $\mathrm{F} 6$ and $\mathrm{F} 8$ were plotted to determine the spurt loss. Figure 7 shows these plots.

According to Darley et al. (2011), during static filtration the fluid loss is proportional to the square root of time; therefore, when plotting a graph of the fluid loss versus the square root of time ( $F L x$ $t^{1 / 2}$ ), the point where the curve touches the $y$ axis shows the spurt loss value. The main cause of this initial loss is that there is a tendency for smaller particles to pass through the filter media before there is any blockage of the pores by the mud cake, whereby only the filtrate will pass. Thus, the values found for fluids F6 and F8 were 0.90 and $3.4 \times 10^{-4}$ $\mathrm{L}$, respectively. Fluid F8 showed lower and therefore better value for spurt loss, indicating that higher amounts of thin particles are present in its composition.

\section{CONCLUSIONS}

From the experiments described in this work, one can conclude that the concentrations of starch and HV-CMC statistically affect apparent and plastic viscosities. Considering the yield limit of drilling fluids, at a $95 \%$ confidence level, for these properties, the highest values were obtained for fluids with $0.0343 \mathrm{~kg} / \mathrm{L}$ of starch and $0.0043 \mathrm{~kg} / \mathrm{L}$ of HV-CMC. Furthermore, it was observed, from the rheological standpoint, that the association of higher concentrations of starch and HV-CMC in drilling fluids inhibited with potassium citrate being more effective for the proper performance of its functions, as well as to the success of the drilling operation.

It was also found that additives such as starch, $\mathrm{HV}-\mathrm{CMC}$, and calcite influence the filtration properties of drilling fluids. The use of either starch and calcite in high concentrations, or starch, HV$\mathrm{CMC}$, and calcite in high concentrations, in waterbased fluids, lead to satisfactory values of API fluid loss, as much as $6.0 \times 10^{-3} \mathrm{~L}$, which represents a decrease of about six times compared to the fluid without additives.

As for the spurt loss, the lowest and best value was obtained for the fluid with high concentrations of starch, HV-CMC, and calcite, indicating that this fluid is composed by a higher quantity of solid particles, and the formation of the mud cake occurs more rapidly.

\section{ACKNOWLEDGEMENTS}

The authors acknowledge the Instituto Brasileiro de Petróleo, Gás e Biocombustíveis-IBP, the PRH-25, and CNPq for finacial support (Process No 305729/2010-1); Company System Mud, an Imdex Limited, for supplying the additives; and the Laboratory of Research in Drilling Fluids (PeFLab, UFCG, Brazil) for the use of their facilities. 


\section{REFERENCES}

Amorim, L.V. Melhoria, proteção e recuperação da reologia de fluidos hidroargilosos para uso na perfuração de poços de petróleo. 326 p. PhD Thesis. Federal University of Campina GrandeUFCG: Campina Grande/ Brazil, 2003. (in Portuguese)

Anderson, R.L.; Ratcliffe, I.; Greenwella, H.C.; Williams, P.A.; Cliffe, S.; Coveney, P.V., Clay swelling - A challenge in the oilfield. Earth-Science Reviews, v. 98, p. 201-216, 2010. http://dx.doi.org/10.1016/j.earscirev.2009.11.003

API RP 13B-1, Recommended practice standard for field testing water-based drilling fluids, 2003

API, Petroleum and natural gas industries - Field testing of drilling fluids - Part 1: Water-based fluids, ISO/WD 10414-1 e ISO TC 67/SC 3 N, 2005.

Boek, E. S.; Coveney, P. V.; Skipper, N. T. Monte Carlo molecular modeling studies of hydrated $\mathrm{Li}^{-}$, $\mathrm{Na}^{-}$, and $\mathrm{K}^{-}$smectites: Understanding the role of potassium as a clay swelling inhibitor, Journal of the American Chemical Society, v. 117, p. 1260812617, 1995. http://dx.doi.org/10.1021/ja00155a025

Chilingarian, G. V.; Vrabutr, P., Drilling and drilling fluids. Developments in Petroleum Science, Elsevier, v. 11, 1983.

Darley, H.C.H.; Gray, G.R; Caenn, R. Composition and properties of drilling and completion fluids. Houston: Gulf Professional Publishing Company, 2011. 720p.

Ding, Y.; Longeron, D.; Renard, G.; Audibert, A. Modeling of both near-wellbore damage and natural cleanup of horizontal wells drilled with water based drilling fluids. SPE-Society of Petroleum Engineers, Paper 73733, 2002.

Dzialowski, A.; Hale, A.; Mahajan, S. Lubricity and wear of shale: effects of drilling fluids and mechanical parameters. SPE/IADC Drilling Conference. SPE, Amsterdam, p. 25730. February, 1993.

Farias, K. V., Influência de umectante aniônico na reologia e espessura do reboco de fluidos hidroargilosos. 88 p. Masters Dissertation. Federal University of Campina Grande-UFCG: Campina Grande/ Brazil, 2005. (in Portuguese).
Guimarães, I. B.; Rossi, L. F. S. Estudo dos constituintes dos fluidos de perfuração: proposta de uma formulação otimizada e ambientalmente correta. In: XVII Brazilian Congress of Chemical Engineering, 2008, Recife, PE.

Hamida, T.; Kuru, E.; PIckard, M. Filtration loss characteristics of aqueous waxy hull-less barley (WHB) solutions. Journal of Petroleum Science and Engineering, v. 72, p. 33-41, 2010.

http://dx.doi.org/10.1016/i.petrol.2010.02.006

Lomba, R. F. T.; Chenevert, M. E.; Sharma, M. M. The role of osmotic effects in fluid flow through shales. Journal of Petroleum Science and Engineering, v. 25, p. 25-35, 2000. http://dx.doi.org/10.1016/S0920-4105(99)00029-7

Lomba, R., Fundamentos de filtração e controle das propriedades de filtração, Report, 2010. (in Portuguese).

Lucena, D. V. Desenvolvimento de fluidos de perfuração com alto grau de inibição ambientalmente corretos. 142 p. Masters Dissertation. Federal University of Campina Grande-UFCG: Campina Grande/ Brazil, 2011. (in Portuguese).

Meng, X.; Zhang, Y.; Zhou, F.; Chu, P.K. Effects of carbon ash on rheological properties of waterbased drilling fluids. Journal of Petroleum Science and Engineering, v. 100, p. 1-8, 2012

http://dx.doi.org/10.1016/i.petrol.2012.11.011

Mohamed, K.; Jean, P.C.; Faiza, B.; Karim, F.; Malika, K.; Nathalie, C.; Abdelbaki, B. Shale problems and water-based drilling fluid optimization in the Hassi Messaoud Algerian oilfield. Applied Clay Science, v. 49, p. 383-393, 2010. http://dx.doi.org/10.1016/i.clay.2010.06.008

Qu, Y.; Lai, X.; Zou, L.; Su, Y. Polyoxyalkyleneamine as shale inhibitor in waterbased drilling fluids. Applied Clay Science, v. 44, p. 265-268. 2009.

http://dx.doi.org/10.1016/j.clay.2009.03.003

Rabe, C. Estudo experimental da interação folhelho-fluido de perfuração através de ensaios de imersão. 290p. PhD Thesis. Pontifical Catholic University of Rio de Janeiro, 2003. (in Portuguese). 
Rodrigues, M.I.; lema, A.F. Planejamento de experimentos e otimização de processos. Campinas: Cárita Publisher, 2010. 358p. (in Portuguese).

Sherwood, J. D.; Meeten, G. H. The filtration properties of compressible mud filtercakes. Journal of Petroleum Science and Engineering, v. 18, p. 7381, 1997.

http://dx.doi.org/10.1016/S0920-4105(97)00005-3

Statsoft, Inc., 2004. STATISTICA for Windows, version 5.0, $1 \mathrm{CD}$.

Steiger, R.; Leung, P. K., Quantitative determination of the mechanical properties of shales. SPE Drilling Engineering, Paper 18024, v. 7, n. 3, p. 181-185, 1992.
Suter, J. L.; Coveney, P. V.; Anderson, R. L.; Greenwell, H. C.; Cliffe, S. Rule based design of clay-swelling inhibitors. Energy e Environmental Science, v.4, p. 4572-4586, 2011. http://dx.doi.org/10.1039/c1ee01280k

Van Oort, E. On the physical and chemical stability of shales. Journal of Petroleum Science and Engineering, v. 38, p. 213-235, 2003.

http://dx.doi.org/10.1016/50920-4105(03)00034-2 